\title{
Overview on Mission Planning System
}

\author{
Zhao Tian, Zhang Wei, Lv Yaoping, and Pan Xianjun
}

\begin{abstract}
As a new type of information network system, Mission Planning System has become the new focal point, especially in the sphere of military technology. In order to guide further research of Mission Planning System, this paper has done several works as below. Firstly, referred to levels of mission, types of missions and the arms and services, mission planning systems are classified in this paper. Subsequently, this paper analyzes the development of mission planning system in US Forces and in other countries' forces. Finally, based on analyzing the experiences, the advices are given for the construction of mission planning system.
\end{abstract}

Index Terms-Mission planning, mission planning system, joint operation, command and control.

\section{INTRODUCTION}

In modern information warfare, there are complicated battle environment and multidimensional battle space. High-tech weapons and new operation patterns are keeping developing. Modern information warfare needs the new technologies of command and control, for example, Mission Planning System (MPS). MPS is a new type of information network system [1], which is based on modern information technologies, with the system target on missions, integrate the military minds, analyze the elements of battle [2], standardize the process of commend and decision, coordinate the simultaneous operations, control the process of operations, evaluate the effects of operations, re-plan the operations on time, evade the conflicts of resource, and maximize the effects of operations. In order to support the whole process of command and control, include of organization, preparation, implementation and evaluation, MPS offer the optimum or suboptimum schemes for military operations. The objects of MPS can cover all spheres of military systems. The resource of MPS includes military personnel and weapon systems. The operation of MPS focuses on command and control. Therefore, this paper, which is focus on development statements and construction experiences of MPS, has very importance sense in both theory and realism.

The basic framework of Mission Planning System includes input information, core database and decision module. The input information of Mission Planning System include operation missions, operation resources and operation objects and so on. The key point module of Mission Planning System

Manuscript received August 20, 2015; revised October 27, 2015.

Zhao Tian and Pan Xianjun are with the Company of Postgraduate Management, Academy of Equipment, Huairou, Beijing, China (e-mail: ianworkmail@sina.com).

Zhang Wei and Lv Yaoping are with the Department of Equipment and Command, Academy of Equipment, Huairou, Beijing, China.

Pan Xianjun is with the Company of Postgraduate Management, Academy of Equipment, Huairou, Beijing, China. is core databases which include data, models and standards. Decision module of MPS includes expert system, assessment system and deduction system etc. By core databases' calculation of the input information, the preliminary plans, something like subsidiary missions, subsidiary dispatch plans, subsidiary model matching plans and subsidiary resource allocation plans can be offered. In decision module, the preliminary plans will be rearranged, assessed and deduced, and the final operation plan will be offered. Fig. 1 shows the basic framework of Mission Planning System.

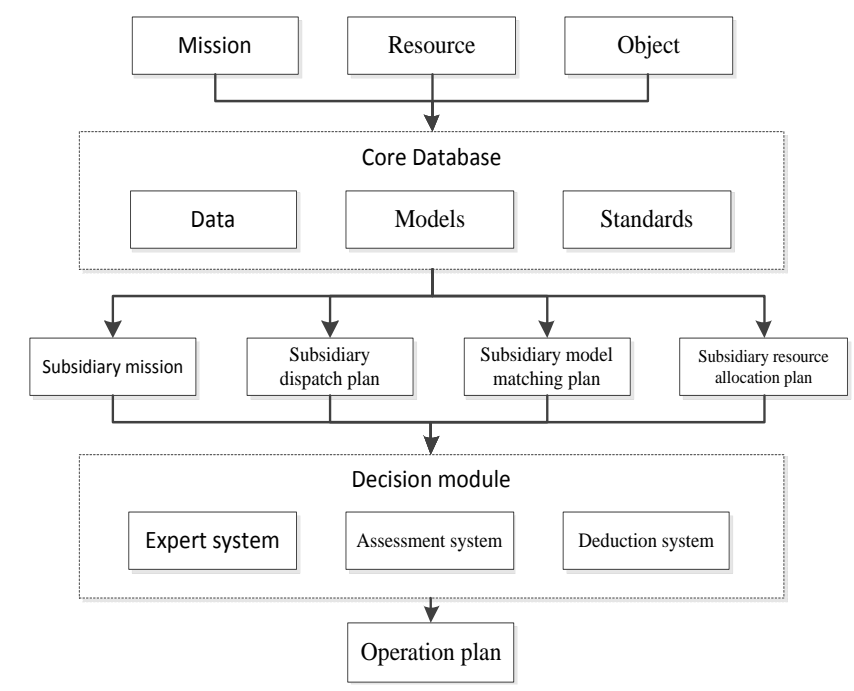

Fig. 1. Basic framework of mission planning system.

\section{ClassiFiCATION}

Under the necessity of missions and sources, MPS can offer effective decision supporting in operations optimization, management and control. Focus on classification of MPS, Chinese and foreign scholars have different research results. But the basic elements are likely to be similar. According to the characteristics of objects, sources, operations and so on, there are multiple methods of MPS classifications. For example, according to levels, there are Strategy MPS, Theater MPS and Tactic MPS [3]; to missions, there are Combat MPS and Support MPS [4]; to services, there are Army MPS, Navy MPS, Air Forces MPS and Joint MPS; to operation applying, there are Command Object MPS and Combat Object MPS; to disposing method, there are On-line MPS and Off-line MPS. Table I shows the primary classification of Mission Planning System in modern research

\section{A. Strategy MPS, Theater MPS and Tactic MPS}

The development of modern Mission Planning System focus on Theater MPS and Tactic MPS. It is a process from uncomplicated system to complicated system, from single function to comprehensive integration. As Strategy MPS, it is a theoretical conception with un-hypostatic system. But some 
kinds of Theater MPS have a sort of Strategy MPS' characteristics.

\section{B. Combat MPS and Support MPS}

The original system of Mission Planning was Combat MPS. But the support of logistics and equipment play a major role in modern warfare to keep fighting capacity. Therefore, scholar are exploding the research of Support MPS.

\section{Command Object MPS and Combat Object MPS}

The main functions of Command Object MPS, which include situation evaluation, scheme formulation and scheme selection, are allocating the operation resources for operation objects. It has main functions of mission receive, situation integration, path planning, fire planning and deduction evaluation etc. To certain extent, the input of Combat Object MPS is Command Object MPS' output.

\section{On-line MPS and Off-line MPS}

On-line MPS and combat objects are banded together. It focus on real-time and flexibility of system. Off-line MPS is separated from combat objects. There are ample resources for powerful and abundant functions.

TABLE I: CLASSIFICATIONS OF MPS

\begin{tabular}{|c|c|c|c|}
\hline Reason & Source & Classification & Typical System \\
\hline \multirow{3}{*}{ Levels } & \multirow{3}{*}{ System Practice } & Strategy MPS & \\
\hline & & Theater MPS & $\begin{array}{c}\text { Joint Operations Planning and Execution System (JOPES) } \\
\text { Advanced Planning System (APS) } \\
\text { Theater Battle Management Core Systems (TBMCS) }\end{array}$ \\
\hline & & Tactic MPS & $\begin{array}{l}\text { Mission Support System (MSS) } \\
\text { Block IV etc. }\end{array}$ \\
\hline \multirow[b]{2}{*}{ Missions } & \multirow[b]{2}{*}{ Theoretical Research } & Combat MPS & \\
\hline & & & \\
\hline \multirow[t]{2}{*}{ Operation applying } & \multirow[t]{2}{*}{ Theoretical Research } & Command Object MPS & $\begin{array}{c}\text { Joint Operations Planning and Execution System (JOPES) } \\
\text { Advanced Planning System (APS) } \\
\text { Navy Mission Planning System (NMPS) } \\
\text { Joint Mission Planning System (JMPS) }\end{array}$ \\
\hline & & Combat Object MPS & $\begin{array}{c}\text { Mission Support System I (MSS I) } \\
\text { Mission Support System II (MSS II ) } \\
\text { Block IV etc. }\end{array}$ \\
\hline \multirow{2}{*}{ Disposing method } & \multirow{2}{*}{ System Practice } & Off-line MPS & \\
\hline & & On-line MPS & \\
\hline \multirow{5}{*}{ Services } & \multirow{5}{*}{ System Practice } & Army MPS & Terrain Mission Planning System (TMPW) \\
\hline & & Navy MPS & $\begin{array}{c}\text { Tactical Aircraft Mission Planning System (TAMPS) } \\
\text { Navy Mission Planning System (NMPS) }\end{array}$ \\
\hline & & & \\
\hline & & Air Forces MPS & $\begin{array}{c}\text { Air Force Mission Support System (AFMSS) } \\
\text { Advanced Mission Planning Appliance (AMPA) } \\
\text { CINNA }\end{array}$ \\
\hline & & Joint MPS & Joint Mission Planning System (JMPS) \\
\hline
\end{tabular}

\section{STATUS}

The West are leading in advanced technology and equipment of MPS in the world, especially, American. US Forces have abundant experiences in MPS.

\section{A. Status of US Forces' MPS}

The major research areas of US Forces are Tactic MPS and Theater MPS, which include Army MPS, Navy MPS, Air Forces MPS and Joint MPS [5]. Some kinds of Theater MPS have a sort of Strategy MPS characteristics.

\section{1) Tactic MPS}

In the 1980s, US Forces developed Tactic MPS [6], and gone through three primary phases: assistant calculation, auto planning and joint planning.
In initial phase. US Forces developed Computer-Aided Mission Planning System (CAMPS), which have assistant calculation function. The typical system of CAMPS are Mission Support System I(MSS I) and Mission Support System II (MSS II) [7]. US Forces equipped on F-15 fighter and F-16 fighter with MSS I and MSS II. In Gulf War, because of implement of MSS II, the hit rates of precision-guided weapons showed huge improvement. But, the initial systems of Tactic MPS equipped a few type of weapons, had a lower degree of automation and complicated to operate. In practice, it would take dozens of hours to complicate one air route.

In second phase. Basic on the experiences of MSS I and MSS II [8], US Forces developed MSS IIA, MSS II+, MSS II Block, Block IV etc. which had auto planning functions. In 
cruise missile MPS, because of Block IV and continued models added the functions of mission re-planning, damage assessment, condition monitoring etc., the budget of warfare cost down and the efficiency of warfare showed huge improvement. According to statistical date, the average mission planning time of Tomahawk cruise missile cost $72 \mathrm{~h}$ in Gulf War, 101min in Kosovo War and 19 min in Afghanistan War. Over the same period, US Forces gradually integrated exiting MPS in same services. For example, Terrain Mission Planning System (TMPW) of US Army, Air Force Mission Support System (AFMSS) [9] of US Air Force, Tactical Aircraft Mission Planning System (TAMPS) [10] and Navy Mission Planning System (NMPS) of US Navy and so on. In the Desert Operation, in order to support Air-Land Battle, NMPS [11] worked out the coordinated plans of aircraft and cruise missile. The second generation MPS took date integration technology, solved the problems of low universality and poor automation, had better function of auto planning.

In third phase. US Forces haven't realized the importance of Joint MPS until the problems of interworking had been exposed in Bosnia-Herzegovina War. According to JOINT VISION 2020, US Forces started research and development of Joint Mission Planning System (JMPS) [12]. In framework of Network-Centric Warfare, JMPS applied structure programming modular, integrated exiting systems of Army MPS, Navy MPS and Air Force MPS, satisfied the requirements of multi-equipment, multi-mission and multi-scale, achieved the goals of Joint Operation. So far, JMPS have been equipped various equipment, such as fighter aeroplane, unmanned aerial vehicle, bombardment aircraft, helicopter and so on.

Fig. 2 shows the development of Tactic MPS in US Forces.

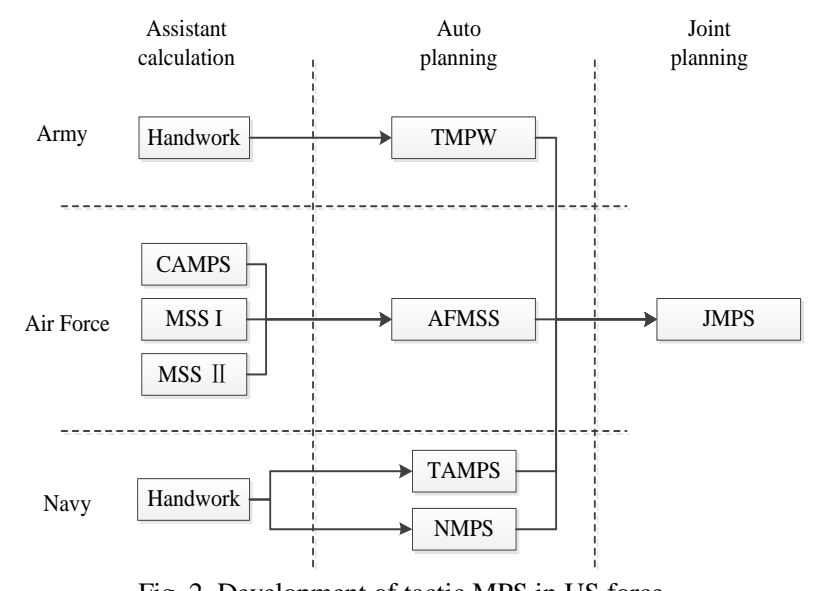

Fig. 2. Development of tactic MPS in US force.

\section{2) Theater MPS}

The typical theater MPS of US Forces are Joint Operations Planning and Execution System (JOPES) [13], Advanced Planning System (APS) [14] and Theater Battle Management Core Systems (TBMCS).

In the 1960s, US Forces started theater MPS research, and developed Joint Operations Planning System (JOPS) and Joint Deployment System (JDS) as Computer-Assisted System. In the 1980s, in order to satisfy Information Joint Operation, they developed JOPES which was based on JOPS and JDS. JOPES was in charge of theater headquarter. It integrate operation standards with operation process for all services, and it could offer joint theater operation plans for US Forces. JOPES had been practice in several high-tech regional wars, such as Gulf War, Kosovo War etc.

APS was a very important system of theater mission planning, command and control for US Air Force. It could offer multi-functions such as situation analysis, threat forecast, routes planning, scheme evaluation etc. and take the characteristics of higher efficiency, lower budget and shorter period.

In the 1990s, in order to satisfy Air Joint Operation, US Forces developed Contingency Tactic Automated Planning System (CTAPS), which had the functions of instruction setting and allocation for air missions. Subsequently, basic on CTAPS, they developed TBMCS. TBMCS was equipped in 2000, and been practiced in Iraq War in 2003. TBMCS successfully offered mission plans for more than 40,000 missions of air-attack operation in one phase of the warfare. Since 2004, in order to satisfy Network-Centric Warfare, US Forces has developed Army Battle Command System (ABCS) which is based on the basic framework of TBMCS.

\section{B. Status of Other Countries' MPS}

In the influence of warfare efficiency for US Forces MPS, Other countries, like Britain, France, China etc., focused on research and development of MPS.

The typical MPS of UK are Pathfinder 2000 [15] and Advanced Mission Planning Appliance (AMPA). Pathfinder 2000 applied structure programming modular of software and hardware, had the functions of routes planning and simulation evaluation, could offer Air-Land attack plans for IDS in Gulf War. Because of the weakness of information processing ability for Pathfinder 2000, UK developed AMPA, which could offer mission planning for Harrier Jet, IDS and Eurofighter Typhoon to combat in nighttime and bad weather.

Main MPS of France are MIPSY, CINNA and CIRCE [16]. With more than 30 years development of France MPS, it has got impressive achievement. For example, CINNA equipped Dassault Mirage since 1982, and offered air attack plans for Kuwait Air Force in Gulf War.

Chinese also paid attention to the research of MPS. Meanwhile, based on Combat MPS, they are exploding the research of Support MPS.

\section{EXPERIENCES AND COUNTERMEASURES}

Review on the development history of MPS, especially in US Forces, abundant experiences can be summed up, meanwhile, beneficial countermeasures can be supported for subsequent development.

\section{A. Experiences}

According to MPS development histories of The West, we can summarize several experiences.

Firstly, continue development. As the core technique of new military minds which include Network-Centric Warfare, Air-Land Warfare and so on, the research and development of US Forces MPS started from 1960s. Although the processes of development were experienced multiple adjustments, but they persisted in developing all the time. 
Secondly, step-by-step development. From assistant calculation to auto planning, from single function to comprehensive integration, from tactical MPS to joint theater MPS. Following the step by step principle, the quality and efficiency of MPS can be assurance. So far, MPS of US Forces can satisfy all missions which were planning in Joint Vision 2020.

Thirdly, joint development. In framework of Network-Centric Warfare, US Forces broken down the situation of "chimneys" MPS development, improved the ability of joint mission planning, integrated exiting MPS to satisfy the requirement of Joint Operations.

Fourthly, integrated development. The emphasis of MPS development are integrating military minds and high technologies. Based on modern information technologies, by integrated military minds, standardization regulations, command process and planning technologies, the operation plans could materialize.

Finally, fundamental development. US Forces focus on fundamental subjects, especially data, models and standards. In order to make sure the sustainable development of MPS, they insist on the harmonious development of systems and fundamental subjects, and updated on time.

\section{B. Countermeasures}

Firstly, top-level design. In respect of military requirement for Joint Operation-oriented, we have to ascertain the relationship between command flow, control flow and information flow. In respect of engineering technologies, we have to construct united framework of standardization, which could cover all levels, all services and all specialties, to satisfy integrative joint operations.

Secondly, reference and innovation. We have to reference the international advanced experiences, study the subjects of military minds, organization processes, standardization files, basic theories, modeling methods, engineering technologies and so on. Meanwhile, we have to find out the practical requirement, innovate new theories and technologies.

Thirdly, fundamental subjects. We have to make a point of fundamental subjects, such as theories, models, data, standards and so on, to provide a thorough grounding for the development of MPS.

Finally, construction and applying. We have to harmonize construction and applying, use typical system to propel all-round development, meanwhile, pay attention to find out problems and sum up experiences.

\section{CONCLUSIONS}

MPS is the products of modern information technologies. It has important military value and forecasted application future in Information Warfare. In the further research, we will focus on the subjects of framework, system functions, operation mechanism etc.

\section{REFERENCES}

[1] H. B. Mao, UAV Misson Planning, 1rd ed., National Defence Industry Press, 2015.
[2] X. Y. Liu, X. L. Huang, and Q. Wu, "The review on the development of mission planning system in foreign countries," Fire Control and Command Control, vol. 32, no. 6, Jun. 2007.

[3] R. Zhou, X. J. Cheng, and Z. J. Chen, "Tactical mission planning systems for modern fighter plane," Control and Decision. vol. 19, no. 4, Apr. 2004.

[4] L. Y. Cheng, J. Ch. Zhu, and J. W. Cai, "Research on framework of aerial equipment mission planning system," Armament Automation, vol. 27, no. 11, 2008.

[5] J. J. Yan, H. Y. Yuan, Sh. Y. Guan, and X. W. Qin, "Mission planning technology based on systems counterwork," Tactical Missile Technology, May 2010.

[6] X. D. Miu and Y. Ch. Wang, Mission Planning Theory and Application for Air Defense of Naval Vessel Formation, 1rd ed., National Defence Industry Press, 2013.

[7] G. M. Levchuk, Y. N. Levchuk, J. Luo, K. R. Pattipati, and D. L. Kleinman, "Normative design of organizations-Part I: Mission planning," IEEE Transactions on Systems, Man, and Cybernetics, vol. 32, no. 3, pp. 346-359, May 2002.

[8] Y. J. Tan, J. F. Li, and Y. F. Xu, "Techniques of military mission planning and control," Military Operations Research and System Engineering, vol. 24, no. 4, Dec.2010.

[9] L. Lei, "Research on wartime airforce weapon support mission planning based on AWSTL," M.S. thesis, Chn., National Defense Technology Univ., Changsha, China, 2007.

[10] (January 1999). Tactical automated mission planning system (TAMPS) $[\mathrm{EB} / \mathrm{OL}$ [Online]. Available: http://www.fas.org/man/dod-101/sys/ac/equip/afmss.htm.

[11] J. Q. Wei, J. J. Yan, Y. H. Yuan, and H. Y. Zhu, "Development of the mission planning in information-based warfare," Tactical Missile Technolog, no. 3, May 2012.

[12] B. F. Chen, "An approach to mission planning system of foreign forces," Ship Electtronic Engineering, vol. 33, no. 9, 2013.

[13] C. L. Shen, J. Chen, and N. Wang, "Overview of air vehicle mission planning techniques," Acta Aeronautica ET Astronautica Sinica, vol. 35, no. 3, March 2013

[14] J. F. Wang, "Functional design of aircraft mission planning system," Ship Demonstration, no. 4, 2011.

[15] M. Zh. Yang, "Overview on foreign air force mission planning system," Air Force Equipment Research, vol. 1, no. 5, Oct. 2007.

[16] X. J. Liu, F. Gao, and H. Xue, "Research on technology of mission planning for precision-guided weapon," Journal of Technology and Research, vol. 26, no. 4, Jul. 2010.

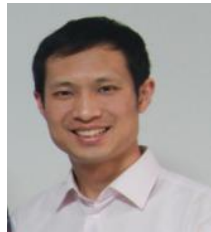

Zhao Tian is a doctoral student in military equipment at Academy of Equipment in Huairou, Beijing. He has 3 years of experience in modeling and simulation as applied to equipment support and equipment manage. Mr. Zhao received his M.S. in combat command from Guilin Air Force Academy in 2009.

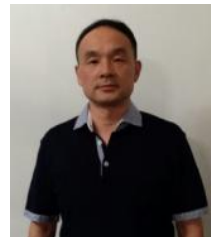

Zhang Wei is a professor in military equipment at Academy of Equipment in Huairou, Beijing. He has accumulated abundant teaching research and practice experience as applied to equipment command support and manage. Mr. Zhang received his D.S. in educational economy an management from Beijing University of Aeronautics and Astronautics in 2011.

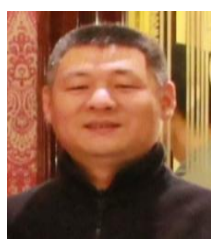

Lv Yaoping has accumulated abundant experience in informatization management of equipment support. Mr. $\mathrm{Lv}$ received his D.S. in management engineering from Academy of Ordnance Engineering in 2008.

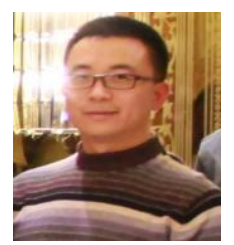

Pan Xianjun is a doctoral student in military equipment at Academy of Equipment in Huairou, Beijing. He focuses on the sphere of RMS and parallel system. 